\section{Journal of Prosthodontics on Complete and Removable Dentures}

Authors: Jonathan P.Wiens /

Jennifer Wiens Priebe / Donald A. Curtis

Publisher: John Wiley \& Sons, Inc, USA

Language: English

ISBN: 978-1-119-44264-6

Edition: 1/e

Published: 2018

Pages: 228, illustrated

Price: $100.99 \$$

\section{Journal of \\ Prosthodontics}

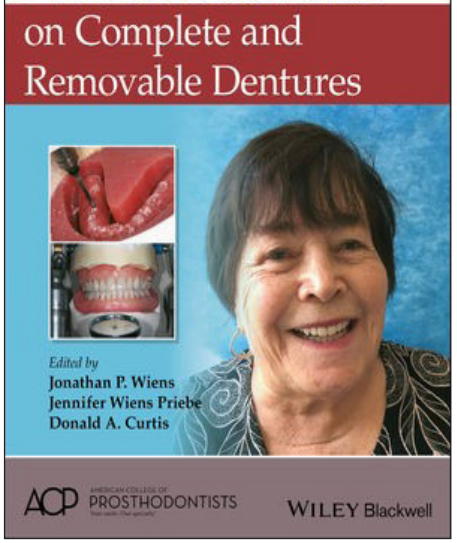

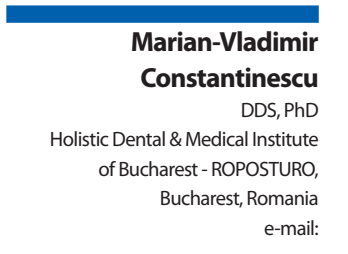

dr.vladimir.constantinescu@gmail.com

The book entitled "Journal of Prosthodontics on Complete and Removable Dentures" includes a compilation of 30 most influential articles by experts in this field. The book is divided into five parts.

Part I, namely "Edentulism and Comorbidities", is based on evidence-based guidelines for the care and maintenance of complete dentures by the American College of Prosthodontists, and presents the systems of classification of comorbid diseases, prosthodontics, diagnoses in oral cancer, current and future treatment of the edentulism, the impact of various prosthodontic treatment modalities on nutritional parameters, conventional rehabilitation and dentures which are a reservoir for respiratory pathogens.

Biofilms, denture stomatitis, clinical and histological findings and evidence regarding the treatment of denture stomatitis are collected in Part II.

Part III, namely "Treatment Innovations" exemplifies the fabrication of complete dentures with CAD / CAM and RP technologies, the part-digitization of impression and interocclusal records, as well as the design by adopting CAD for fixed prostheses and optimizing outcomes with tissue management and impression technics.

The position of the occlusal plane in the natural and artificial dentitions, the prediction of satisfaction, the analysis of the masticatory cycle efficiency, the evaluation of the OHIP-14 scale and the factors associated with successful dental therapy are the subject of the "Functional Parameters and Assessment", Part IV.

The last part, "Esthetic Considerations", discusses the perception of the esthetic impact of the smile line by different age groups, the assessment of the ability to relate anterior tooth form and arrangement to gender, guidelines for maxillary, incisional edge position, nasal width as a guide for the selection of maxillary anterior teeth in four racial groups and the selection and arrangement of the maxillary anterior teeth.

Reading this book, the practitioner comes into contact with the latest and relevant information on the edentulous patient, which will serve him in making dentures as efficient as possible and in accordance with the needs of his patient.

DOI: http://www.stomaeduj.com 10.25241/stomaeduj.2019.6(2).bookreview.4

The Books Review is drafted in the reviewer's sole wording and illustrates his opinions. 